\title{
WHY HAL 9000 IS NOT THE FUTURE OF INTELLIGENCE ANALYSIS: INTELLIGENCE ANALYSIS IN THE 21ST CENTURY
}

\author{
Giangiuseppe Pili, Intelligence Lab, University of Calabria
}

\begin{abstract}
Intelligence analysis is a core function of the intelligence process, and its goal is to synthesize reliable information to assist decision-makers to take a course of action toward an uncertain future. There is no escape from uncertainty, friction, and the fog of war. Since the dawn of human history, the present moment has been experienced as unpredictable, and the challenge of determining the right future through sound decisions has always existed. Investing in new technology, continually touted as the answer for analytic troubles, seems far less difficult in the short run than trying to find consensus about a long-term vision. It is easier to develop a nuclear missile, for example, than to give a universal definition of peace, and this is what the history of the $\mathrm{XX}$ century was all about. While intelligence analysis is still a necessary tool for decision-makers, it is unclear who or what will perform this function in the future. Though the solution cannot be only technological, the current trajectory tells a different story whereby the human analysts are removed from their central position to make way for Artificial Intelligence.

What one can reasonably ask of an officer is that he should possess a standard of judgment, which he can gain only from knowledge of men and affairs and from common sense.

Carl Von Clausewitz - On War
\end{abstract}

HAL: Let me put it this way, Mr. Amor. The 9000 series is the most reliable computer ever made. No 9000 computer has ever made a mistake or distorted information. We are all, by any practical definition of the words, foolproof and incapable of error.

Stanley Kubrick - 2001 - A Space Odyssey

\section{Introduction}

Intelligence analysis is a core function of the intelligence process, and its goal is to synthesize reliable information to assist a decision-maker to take a course of action toward an uncertain future. There is no escape from uncertainty, friction, and the fog of war. Since the dawn of human history, the present moment is characterized as unpredictable, and the challenge of determining the right future through sound decisions has always existed. Over time, the competitive environment drove and encouraged the development of intelligence units and compartments. Multinational companies invested in new technologies anticipating that the state of security intelligence would want to develop an intelligence capability to perform intelligence analysis. After the trauma of two world wars, a further factor that boosted intelligence 
growth was the two main superpowers' inability to fight openly. The Cold War was an epistemic war, namely a war whose goal and means are the control of the enemy's knowledge and information (Pili, 2015). The two blocks then competed through the systematic use of all their intelligence capabilities, including intelligence analysis. This intelligence arms race, combined with the traditional arms race, ultimately led to a revolution in military affairs, as well as a revolution of information, the internet, and the hi-tech industry of the day.

The exploration of the future of intelligence analysis is the primary goal of this study. There is no question that intelligence analysis will be important in the future; however, intelligence analysts' roles will be under pressure from the development of new 'smart' technologies. The question is whether or not intelligence analysts will be a necessary part of the future intelligence process, and what their working environment will look like.

First, a research framework is necessary to ground the paper's main argument, which is the outlook of intelligence analysis in the age of perpetual informational and technological development. Second, the intelligence analysis and analysts' necessity within the intelligence process will be scrutinized as preliminary steps for the main argument. The focus will then turn to the nature and role of the new technologies and the analysts' interaction. Finally, the conclusion will summarize the main results: if in the past was easier to develop a nuclear missile than to agree on a common definition of peace and its conditions, in the future, we will see an imbalance in the relationship between analysts and machines.

\section{Intelligence Analysis - The Intelligence Studies Framework}

Intelligence Studies (IS) generally consider intelligence analysis a core function of intelligence, and it is certainly one of the most explored topics in the field of IS. Depicting IS's current topology and dimensions would be worthwhile because it would illuminate how different parts of the intelligence process and cycle are variously studied and understood. For instance, the phases of collection and intelligence management seem less relevant to the IS discussion than intelligence analysis, and while it would be premature to establish the causes of this perception, they probably lie in the history and nature of IS as a research endeavor. Sherman Kent was one clear leader toward the focus on the analytical component of the intelligence function (Kent, 1951). However, IS is still a new scientific branch (comparatively speaking), and its resources cannot be compared to those of an established hard science like physics or chemistry, already centuries old. In addition to the lack of time, there continues to be a lack of contribution from global 
sources, which has reduced the evolution speed of intelligence education in the USA and the UK.

This means that we have a conception of intelligence that is very specific, led by the Anglo-Saxon world's experience which, though important, is still a limited view. Given the competitive advantage they have had since the end of the Cold War, or even before, this is understandable. However, because science is a multinational and multicultural human endeavor, this unbalanced knowledge of, and access to, the USA-Five Eyes literature causes a general misperception of the nature of intelligence. For instance, it is not clear whether intelligence analysis reflects the national experience, or in what sense it is similar or dissimilar. Without proper time or resources, intelligence researchers have had to focus their attention on something on which they could have an impact. Intelligence analysis is, therefore, the phase most susceptible to being amended, developed, criticized, and improved by academic researchers with or without the appropriate qualifications. In addition, the intelligence methods employed in intelligence analysis are almost completely available on open-sources, namely scholarly publications. Hence, this research framework is inevitably sided and grounded in the IS literature, with all its pros and cons.

There are at least three different components of the IS debate on the subject. First, scholars try to conceptualize intelligence analysis' goal and means, looking to the broadly understood function of intelligence. In this respect, Stephen Marrin's Intelligence Analysis Theory is still an unmatched work. Marrin develops a theory that is both descriptive and predictive. He first considers the limited resources of the intelligence community to cover all the threats to national security. His approach then tries to capture the attention of intelligence analysts to highlight the future trajectory of the field and, consequently, the allocation and investment of public resources. Intelligence analysis is considered a means to support decision-makers to ground their foreign and national security policies in rational analysis of information. "For a state, the use of intelligence agencies is the most effective and efficient way to provide leaders with the information necessary to use power through its foreign policies effectively and accurately, regardless of whether the force is to be applied for offensive or defensive purposes" (Marrin, 2007, p. 832). However, the theory also has an explanatory component because it shows how intelligence analysis, as a core function of intelligence, is performed to maximize efficiency inside institutions of a certain magnitude. Intelligence can then be considered as a power and efficiency multiplier for the government in foreign policy.

This understanding of intelligence analysis can be further extended to include the private sector. Interestingly, Daniel Yergin's (2012) monumental study

The Journal of Intelligence, Conflict, and Warfare Volume 4, Issue 1 
on the oil and gas industry reports how Standard Oil performed similar intelligence functions to those of the government. Standard Oil and other big companies' behavior show that power has no color or mission, but instead, requires a common practice to maximize its expansion. Intelligence is a key part of this common practice. In fact, this order of things was recognized by great modern political philosophers, such as Niccolò Machiavelli and Thomas Hobbes; the prize is the power, and intelligence analysis plays an important role in this competitive toolkit.

Beyond the general investigation of the intelligence analysis function, there are two major debates. The first explores the study and evaluation of intelligence methods. The second considers the development of standards, responsibilities, and limits of the agencies' analytical branch. At the heart of the debate of intelligence methods, there are Structured Analytic Techniques (SATs), whose introduction was influenced by a neo-classic concept of (hard) science as a benchmark for any kind of human knowledge endeavor. Richard Heuer's investigation could be rightly considered a classic handbook on the psychological and cognitive foundation of intelligence analysis (Heuer, 1999), which developed and expanded the literature on the necessity of the use of SATs. The focus is on the cognitive biases that can hamper the analysts' thinking and, therefore, their output. Though intelligence education is now focused on teaching SATs and emphasizing their importance (Heuer $\&$ Pherson, 2015; Scuola Filosofica, 2020b), there is still a wide debate about their effectiveness (Coulthart, 2016), and their actual employment in the field (Arcos \& Palacios, 2020). Stephen Artner, Richard S. Girven, and James B. Bruce for RAND (2016) recently published a very convincing study on the subject.

The discussion on standards and responsibilities is finally being explored, specifically to include the U.S. investigations and commissions that followed the 9/11 and 2003 Weapons of Mass Destruction (WMD) cases. Interestingly, the scholars' reactions can be as dramatically framed as they were by the retired Director of the National Security Agency (NSA), William E. Odom (2008): "Perhaps the most important point is that intelligence inexorably turns out to be far from what is desired, that it is a gamble, like war itself, and that intelligence chiefs cannot compensate for poor and unlucky command judgment or poor political judgment" (p. 331).

Even from this brief literature survey, several conclusions can be drawn. First, intelligence analysis is a core topic of the IS; second, nobody contests this fact; third, while intelligence methods and techniques are only one component of intelligence analysis, they definitely sit at the center of intelligence education. There is no doubt that SATs, along with other methodologies, are considered a crucial part of intelligence training, at least in universities (BA

The Journal of Intelligence, Conflict, and Warfare Volume 4, Issue 1 
and MA levels). This is especially true in the US (Marrin \& Ciensky, 2019; Scuola Filosofica, 2020b) but less so in the UK (Goodman \& Omand, 2008). However, the centrality of training in SATs is clearly different when comparing American and European universities. However, Rubén Arcos and José-Miguel Placios suggest that the European intelligence agencies' training program indeed focuses on the intelligence tradecraft in detail (Arcos \& Palacios, 2020).

Intelligence analysis standards continue to focus on integrity (of the analysts) and objectivity (of the analysis and report), even if the question remains whether this focus is credible or feasible. Such standards are often unrealistic, impossible to be obtained in practice, and too demanding (Odom, 2008; Lowenthal, 2008). After 9/11 and Iraq 2003, the U.S. Intelligence Community was accused of being unable to provide good analysis. This sometimes degenerated into unfair requests about their analytical capacity. As Mark Lowenthal (2008) beautifully put it: "we need to remember that intelligence analysis is an intellectual process. It needs standards and guidelines, but these alone will not ensure analysis that will produce the 'right' answer. Indeed, there is no way to ensure the 'right' answer" (pp. 313-314). And as Michael Kreuzer (2015) clearly stated: "the Intelligence Community continues to lack a single, coherent understanding of what constitutes intelligence analysis" ( $p$. $6)$.

It is, therefore, reasonable to assume that the discussion on the nature of intelligence analysis will continue, even if its future will have different focuses. First, there is a general necessity to teach intelligence analysis compatibly with several similar but separate professions, mainly those that require information evaluation, monitoring, and refinement to deliver a product, usually an information artifact (Smith, 2012; Smith \& Ceusters, 2015). Second, though the intelligence education will further drive the teaching on SATs and the like, the development of new tools will continue to increase. The so-called information revolution is no longer new, which means that information technology today is more like a changing landscape.

Given the unceasing technological development, present and future analysts have to, and will have to, continuously learn new technologies in order to not be left behind. This is a relentless, unavoidable, and probably painful process. For instance, Efren Torres, in an interview with Scuola Filosofica (2020a), stated that we are already at a mature second-generation stage of Open-Source Intelligence (OSINT) due to new tools developed during the last ten years. Therefore, though the traditional educational approach will remain the same - bringing its controversies with it - the future of intelligence analysis will be decided by technology. As Joseph Gartin (2019) stated: "at no time in my intelligence career have we faced a more fluid analytic landscape.

The Journal of Intelligence, Conflict, and Warfare Volume 4, Issue 1 
Navigating it will be challenging, and in the face of such a challenge knowing where we started is key to charting the future" (p. 1). This leads us to the next step of the argument.

\section{Will Intelligence Analysis Exist in the Future?}

'Will intelligence analysis exist in the future?' is the key question. It is painful to recognize that what lies ahead is difficult to foresee, especially in a field in which recognizing patterns and anticipating threats are the main mission. There is no doubt that policymakers will need intelligence to project power. After all, if there is something the $20^{\text {th }}$ century taught us, it is that statecraft requires intelligence. This is true for democratic states, and it is truer for empires, monarchies, totalitarian regimes, and even despotisms. It is almost a socio-political rule. Where there is an institution that tries to control and expand beyond its limits, there will be somebody who will perform the intelligence function. This is what history has taught us, and by applying a classic inductive rule, we can reasonably infer this will be the case in the future. Beyond history, there are logical, deductive, and compelling arguments that ground this statement, as argued elsewhere (Pili, 2019b, pp. 581-583).

The answer is clear: intelligence analysis will continue to exist because policymakers will need it to pursue their policies. In the same fashion, multinational corporations and company decision-makers will need similarly tailored information to understand the reality of the market, their competitors, and what is required to pursue an active economic campaign abroad. Insofar as there is a market in the public and private sectors for intelligence products, intelligence analysis as an output will survive and, possibly, flourish. So far, so good.

\section{Will Intelligence Analysts exist in the future?}

However, we could reformulate the question in a slightly different way: will intelligence analysts exist in the future? After all, if we can easily conclude that intelligence analysis will survive and even thrive, it seems obvious to arrive at the same conclusions for the analysts. But is this the case? If the intelligence analyst is the cause of intelligence analysis, removing the cause would also remove the effect. But what if we substitute the analyst with a procedural set of events (e.g., a machine) able to achieve the same effect? This 'event' can be identified with different labels. The most fashionable is some complicated algorithm, namely 'artificial intelligence' performed by mechanical calculators without brain-like components.

Considering we do not yet have anything comparable to a human mind and its indeterminist functioning, I will call these series of technologies as they

The Journal of Intelligence, Conflict, and Warfare Volume 4, Issue 1 
are, namely 'efficient smart machines' (ESM). Instead of the vague and allinclusive term 'artificial intelligence,' along with all the related semantic powerful imagination boosters (such as Machine Learning, Deep Learning, and the like), ESM is a description that stands for a mechanism able to perform a task because of its efficiency and, therefore, domain-based smart. It is useless to clarify whether ESMs are intelligent or not. The requirement is that they can solve problems efficiently because of a given 'smart' mechanism, limited to a specific set of inputs, rigid rules, and domain(s). "AI achieves its problem-solving goals by detaching the ability to perform a task successfully from any need to be intelligent in doing so. The App on my mobile phone does not need to be intelligent to play chess better than I do." (Floridi, 2019, p. 9). Just as a machine engine is efficient with the proper fuel in appropriate conditions, these technologies are also smart and efficient under severe constraints, examples of which are that they need to be in a contained artificial environment (inside, temperature controlled, etc.) and are entirely dependent on humans who protect them and fix them.

As the description 'artificial intelligence' is vague, it is better to use the label ESM, which suggests the presence of a deterministic mechanism whose nature is entirely fixed and predictable, looking at its rules and inputs. Ludwig Wittgenstein $(1951)^{1}$ suggested that there cannot be any vagueness in logic this is in the realm of triviality - nothing new has to emerge. Specifically, ESMs are comparatively more efficient because of their own working rules. The ESMs are useful in the presence of a large amount of data to be processed and it is irrelevant whether those data are machines' creations themselves (such as the case of AlphaZero programs - see Silver et al., 2018; Kasparov, 2018; Modern War Institute, 2018; Pili, 2019a), or are given to them as input. The only important point is that their main fuel is precise data typology. Does this fuel remember the prerequisite for intelligence analysis?

Indeed, intelligence analysis is a portion of a more extensive process, which is highly data-driven by its very nature. That is why many experts and scholars repeatedly state that the field of intelligence is complicated by the intrinsic challenges that human cognition faces under time pressure, psychological stress, cognitive overload, and information deluge (Pili, 2019a). In addition, as Odom's quote previously mentioned suggests,

\footnotetext{
${ }^{1}$ For a detailed analysis of Wittgenstein's vision of logic see, Wittgenstein (1921 \&1951), Kenny (1973), Kripke (1982), Proops (2017).

Kenny, A. (1973). Wittgenstein. Harvard University Press.

Kripke, S. A. (1982). Wittgenstein on rules and private language: An elementary exposition. Harvard University Press.

Proops, I. (2017). Wittgenstein's logical atomism. The Stanford Encyclopedia of Philosophy (Winter 2017 Edition). Zalta, E. N. (Ed.).

https://plato.stanford.edu/archives/win2017/entries/wittgenstein-atomism/
}

The Journal of Intelligence, Conflict, and Warfare Volume 4, Issue 1 
understanding human behavior - even before trying to predict it - is quite different from calculating the trajectory of a ballistic missile. This is because humans exercise their will and freedom in the face of all the laws of physics, which are still unable to indicate what an individual will be and do, what the economy will look like, and how battles, wars, and conflicts will end. This is not the statement of a philosopher, but of a former NSA director: "Most important is appreciating that 'voluntarism', or the exercise of 'free will', in the behavior of adversaries cannot be predicted" (Odom, 2008, pp. 327-328). This statement is as true as ever. In this respect, intelligence analysis remains heavily grounded on data-driven processes, fueled by a restricted number of data-domains (the intelligence disciplines).

Let us suppose that we remove old and new data-collections from intelligence analysis. What is left? Not much, I believe, besides the methods. Intelligence analysis is a key component of an informational process, whose main characteristic is being an informational artifact for a conscient decisionmaker. Properly speaking, intelligence analysis is the crucial intersection of the intelligence process. Without analysis, the process would resemble a mere collection of data similar to those performed by simple natural organisms without conscience. These creatures are unable to conceive past, present, or future, and while they are still able to survive in the difficult competitive environment spontaneously offered by the planet Earth, their only defense is their reactive capacity to fight against competitors via a classic Darwinian selective process (Dawkins, 1976; 2016). Indeed, "survival machines [organisms] began as passive receptacles for the genes, providing little more than walls to protect them from the chemical warfare of their rivals and the ravages of accidental molecular bombardment" (Dawkins, 1976, p. 59). In contrast, decision-makers and analysts need to offer more than this.

Humans generally desire to look far into the future to appropriately impact the world today. Decision-makers do not want to merely survive the day; they want to anticipate threats, thereby improving their ability to shape the world using the power granted to them by their company or nation. Mere data collection is also insufficient. The collection of data must be refined, and translated into meaningful information, which then has to be put into context for evaluation, and finally transmitted both in a timely manner and in a format able to be digested by the consumer. The analysis is necessary alongside the entire process engaged to maximize its efficiency. It is not the collector that creates the need for analysis; it is the other way around: The decision implies analysis because, though we live in a neo-probabilistic deterministic universe, to understand it, we need to start from the goal and go backwards to see how it has been performed.

The Journal of Intelligence, Conflict, and Warfare Volume 4, Issue 1 
Therefore, even though energy, computation, information, and time are always necessary and sufficient components of a process, the informational side of intelligence analysis is the pre-eminent cause of its existence in an Aristotelian sense. As such, the intelligence process is a social epistemic activity pursued to provide a particular informational artifact to a human customer. However, the focus is on the customer, not on who or what performs the intelligence process. Therefore, if we substitute the analyst with a machine, whose reliability and accuracy are comparable to the human mind, or even more efficient, what is left to the intelligence analyst? Not much. So, the real quarrel is about the human space within the intelligence process, not the process itself.

\section{Two extreme positions on technology and intelligence analysis}

Since the dawn of ESMs, there have been extreme views on the topic: the triumphalist and the disenchanted. The first position is held by those who believe that programs run by computers offer the best of humanity. They believe the ESMs are relentless, predictable, reliable, and fairly accurate. Even though Alan Turing (1950), in his fundamental Computing Machinery and Intelligence, warned about the perils of not checking their results, there is the common temptation to accept everything the ESMs give us as output. They are seen as much better than a human oracle. They are determinist systems believed to be almost infallible. The advocates of this extreme position see the smart machines as human reasoning without any of the human mind's flaws or fragility. To be clear, only a small percentage would embrace this fringe view; however, the symptom of this perspective usually shows up as the systematic removal of friction posed by nature to everything existing. They tend to isolate the tool from reality, as if a piece of equipment could exist in isolation. In the military domain, a similar attitude is shared by all who believe that the new information technology will soon remove the fog of war. A peculiar variation on this theme is shown by those who fear the dawn of the omniscient machine, able to wipe out human intelligence, and potentially humans.

At the opposite extreme, some see machines as useless adult games, which can be a fun, though, also a scary piece of equipment. The supporters of this view are usually on the critical side of science and technology, which is seen as connected to the endless human effort to control all other beings. Though still powerful, technology is seen as limited exactly for the same reasons the triumphalist believer views it to be almost omnipotent. What are the implications of this twofold understanding of technology - from one side, the triumphalist and from the other, the disenchanted?

The Journal of Intelligence, Conflict, and Warfare Volume 4, Issue 1 


\section{"In future, the analyst's role will fit around the machinery"-Will we eventually be left out?}

Scholars and ex-practitioners, Nick Hare and Peter Coghill (2016), have explored the future of the intelligence analysis topic, and though they are not so triumphalist, they do see a change in the role of the intelligence analyst: "Instead of being the repository for the data (a task to which humans will be manifestly inadequate) the analyst will become a 'curator' - or perhaps 'librarian"” (p. 11). Intelligence analysis will survive because there is the need for it: "Intelligence outputs are whatever intelligence organizations deliver to customers to make their beliefs more accurate and, therefore, their decisions less risky" (Hare \& Coghill, 2016, p. 3).

However, intelligence analysts will work quite differently. They see them working on producing tools to exploit other technology pieces to improve the data refinement and, ultimately, the quality of the intelligence output. Indeed, "what this means is that future human analysts will not be able to interact directly with all the relevant data and information that, in previous eras, they might be expected to know and to reel off as needed" (Hare \& Coghill, 2016, p. 6). Consequently, the analysts, and people in general, will find themselves at a fair distance from that which caused the particular intelligence collection or analysis. In this scenario, the ESMs would reliably perform their calculation while the analysts direct their orchestra of instruments to create unified, coherent music, which still needs to be read by a human (the decisionmaker). As Hare and Coghill (2016) state:

Instead, interaction with data will increasingly be via tools that 'do things' to the data before presenting it (in whatever form) to analysts. These tools will perform a number of functions such as filtering, categorizing, abstracting and visualizing. (...) The effect will be to distance analysts from the data [emphasis added], enabling them to focus on its import and significance from a loftier perspective. (p. 6)

In this respect, the analyst will behave more like a software engineer than a scientist, and in doing so, they will answer the riddle of whether intelligence analysis is an art or a science. It is, in fact, the art of creating a science almost without human input. After all, as Hare and Coghill (2016) state:

In previous epochs, technologies for external information storage and retrieval systems were unwieldy and unreliable, and informationprocessing technology was laborious and expensive to use. Until the proliferation of microprocessors and effectively-free data storage, the human brain was the cheapest, fastest and most versatile instrument available to perform many of these tasks. But this is no longer the case. (p. 7)

The Journal of Intelligence, Conflict, and Warfare Volume 4, Issue 1 
As the philosopher of information Luciano Floridi (2010; 2011; 2019) argued, humans will be put outside the calculator and the calculation in order to protect the machine from human and natural friction. We are reshaping the world to enable the ESMs to work as we need them to but under optimum conditions-by making sure they are given a structured and suitable environment in which to work appropriately. The analysts will still be part of the intelligence analysis function but will be situated at a safer distance. In this way, humans and ESMs together will achieve the best outcomes. As Hare and Coghill (2016) note:

Analysis is a fundamentally cognitive activity. Artificial intelligence is the term we give to tools that are designed to perform cognitive tasks, and over the next couple of decades these tools will become increasingly effective, easier to use and fuelled by boundless data. In future, the analyst's role will fit around the machinery [emphasis added], in the same way that a fighter pilot or car mechanic's role is moulded today. (p. 8)

However, intelligence scholars and many ex-practitioners are against this vision of the future of intelligence analysis and analysts. Though most of them agree with Hare and Coghill (2016) on the new wild race in machine development, they are much more cautious about heralding the dawn of new technologies in intelligence analysis. There are two often identified levels of friction. The first is the human-machine interaction itself. It is neither easy nor straightforward to solve this collaboration puzzle. As Treverton and Gabbard (2008) stated regarding the research and development function:

Too often 'R\&D' [Research \& Development] equals 'tools.' The thrust of our conversations and our analysis is that the equation is wrong. Indeed, tools may be the least relevant $\mathrm{R} \& \mathrm{D}$ product for the analytic community. (...) Tools are helpful but not essential. What are essential are the people skills - training, policy, and leadership. (p. 18)

They go on to add "there is no consensus on the need for or value of 'tools.'" (Treverton \& Gabbard, 2008, p. 19). There is no question that ESMs are needed in the intelligence profession. The question is, to what extent?

It is questionable, then, that a high-tech piece of equipment could provide the solution to intelligence analysis because intelligence analysis is itself part of a political activity: a process generated by complex external friction in which the human factor is a key ingredient. Although the peril of a harmful intelligence politicization is always there, intelligence is still inherently 'politically laden' from within and from without and, therefore, an intrinsically human activity (Pili, 2019b). It is politically laden from within because the policy is defined by human needs, values, and goals which intelligence

The Journal of Intelligence, Conflict, and Warfare Volume 4, Issue 1 
analysts must cope with and which cannot be reduced into a set of rigid rules, as recent studies have clearly showed. This is dramatically clear when ethical or political biases cause misdoings by the ESMs (Silberg \& Manyika, 2019).

Intelligence processes require political values to be performed-'political' meaning simply the evaluation of who constitutes the opponent or enemy. The notion of opponent or enemy itself is normative, and there is no such thing as 'an enemy' in nature. This is why physics is much more difficult, but less complex than intelligence, and it does not offer a valuable comparison in the understanding of whether intelligence is a science or an art. It is a misleading question. On the other hand, intelligence is politically laden from without because the enemy or opponent has a spontaneous tendency to fight back, as Michael Warner (2002) put it some years ago when he had to underline intelligence's nature as part of a broader competitive activity.

Intelligence analysts will be necessary in the future, even in light of intelligence failures; they will not be replaced by high-tech tools even if they sometimes make mistakes: "we will suffer losses on occasion not because intelligence is flawed but because it is human and it is difficult" (Lowenthal, 2008 , p. 315). So, it looks like intelligence analysis will remain humancentric, and the consequences of it will have to be accepted. It could also be argued that intelligence analysis is not analysis but synthesis. As Michael Kreuzer (2015) sharply stated:

Herein lies the first big problem with the working definition of intelligence analysis - by specifying it as a process of creating and delivering intelligence, it actually comes closer to the definition of synthesis than analysis, and in practice means both analysis and synthesis. (p. 7)

Finally, let us imagine that ESMs could perform all intelligence analysis tasks, fusion included - the synthesis of the intelligence analysis component (Kreuzer, 2015; Baker, 1995). There should, then, be another smart machine to double-check its accuracy (the result) and its reliability (how that result was achieved). After all, unless we trust the machine blindly, we should enact some control over it. Considering blind trust is not a rational option for any meaningful intelligence standard-human or not—we need a quality assurance mechanism.

Back in the day, Turing (1950) considered the right process as partially mechanical and partially human. But then, there is an easy infinite regression which culminates in two possibilities: (a) we blindly trust machines (otherwise, we would need an infinite number of machines to check other devices, which is out of the question), or (b) humans check the machines'

The Journal of Intelligence, Conflict, and Warfare Volume 4, Issue 1 
results and operations, such as the method used in chess, a discipline as highly influenced by ESMs as anything else.

\section{The interaction between the ESM race and intelligence analysts}

Intelligence analysis will continue to be an important intelligence function in the 21st century, even when high-tech AI is fully deployed. However, as it has already been underlined, the real issue is the human-machine interaction, and the question of who is more beneficial in the process. There is no question that tools will play a crucial role in the future because they are already the symbol of our time. But to answer the question of ratio in the interaction between the analysts and the ESMs, let us consider what ESMs cannot do, and why the balance between analysts and tools should favor the latter instead of the former.

ESMs are not able to synthesize and integrate information in a human-like way. This is because of how they work. They are analytical tools in the Kantian notion of analysis (Beaney, 2018) - that machines can infer conclusions by their own rules and given available data-but they cannot add new information about the given knowledge already available. They can only clarify it. Naturally, this is the important work they do for us. They do not invent something new in the specific sense that their products are indeed logically trivial. That is why the more we upload information and the more data the machines store, the better they can perform. This is an inter-domain characteristic of ESMs, and it does not look like it will change any time soon.

For the scenario that allows the existence of ESMs, the machines' results will always have to be checked by humans. For instance, despite what Hare and Coghill (2016) argued, we need humans to control the plausibility of the machines' outputs. If the data are biased, then the results will be biased as well. So, if a biased database stored Bach's music as Beethoven's compositions, a machine would always infer that the music was Beethoven's instead of Bach's. It would, therefore, be safer and wiser to have a music expert available to certify whether or not the machine is correct. Thus, Hare and Coghill's (2016) 'librarian vision' of intelligence analysis is not entirely sustainable, unless we want to follow a perilous path - which is indeed the main conclusion of this article. The 'expert' would need to be a trained analyst that has access to different materials and rules of inference than those accessed by the machine.

A machine cannot re-program itself when the environment changes or in the face of threats or serious errors. Even AlphaZero can improve only after thousands of games when encountering a single mistake (Kasparov, 2018). ESMs are selected only in the Darwinian notion of 'artificial selection' and not by natural selection. We - humans — select them for our purposes, though

The Journal of Intelligence, Conflict, and Warfare Volume 4, Issue 1 
they - the machines - generate an artificial selection of humans because only a limited number of people can (a) use them and (b) re-program them. Therefore, humans are still the only entity able to change the perspectives, values, and rules of the machines. Because we are able to develop mathematical ideas and concepts and we are the only entity on Earth able to even understand what a number is, humans are uniquely positioned as the ones who can and must judge whether the machines can compute or not.

There is also a general misconception and abuse of statistics and probability at large. This is true for the intelligence analysts, but it is by far truer for machines. It is common to draw new conclusions from old trends, namely by a sheer probability calculation. However, as shown by the influential economist Mises (1949):

Everything that outside the field of class probability is commonly implied in the term probability refers to the peculiar mode of reasoning involved in dealing with historical uniqueness or individuality, the specific understanding of the historical sciences. Understanding is always based on incomplete knowledge. We may know the motives of the acting men, the ends they are aiming at, and the means they plan to apply for the attainment of these ends. We have a definite opinion with regard to the effects to be expected from the operation of these factors. But this knowledge is defective. We cannot exclude beforehand the possibility that we have erred in the appraisal of their influence or have failed to take into consideration some factors whose interference we did not foresee at all, or not in a correct way. (p. 112)

Furthermore, he argues that categorical probability analysis is a form of deductive reasoning and, therefore, trivial - that is, merely analytical, without integrating new information about the world. And indeed, the result is the recognition of gambling as a form of necessary human action, as Odom (2008) confirms with his comment that the free will aspect of adversaries' behavior cannot be predicted. Therefore, in this respect, ESMs are blind toward the future unless this future is already grounded on a predictive (natural) way.

This also means that machines cannot outperform human analysts in understanding reality, though they can be better in calculating the chances of a given event to happen. But this calculation is entirely based on the exhaustion of the knowledge of the given category. Obviously, the categorical probability deduction is indeed precious to the intelligence analyst exactly because it is just a way to derive evidence and, therefore, it means that a statistical program based on a big data model is insufficient to replace the

The Journal of Intelligence, Conflict, and Warfare Volume 4, Issue 1 
human in charge. Furthermore, if the probability is conceived subjectively (or maybe in the Bayes' formulation), it is an even stronger indication that only an analyst's abilities could arrive at it. Only intelligence analysts are able to understand reality and new variations of it, something which is completely impossible for machines.

ESMs are far from mastering languages in an active sense. Although they are improving to help humans learn and use different languages, this is only possible where there is a mechanical feature of language that can be coded at a level of understanding that does not require grasping meanings and truth values. Finally, even if analysts can have entertaining chats with ESMs on football and politics, the machines will still need 'doctors and nurses', meaning an entire productive and maintained infrastructure similar to the healthcare system for humans.

However, though analysts will have a job in the future, this does not mean the dialectic posed by our time is in their favor. This argument is easy to identify. As previously stated, there is still a wide-open discussion on what intelligence education is, how to train intelligence analysts, and what their core skills should be. However, investment in machines, software, and programs is an easy bet. Funds for machine development are less risky and more appealing than any similar project for human training and education, especially in times in which education is deeply under scrutiny.

So, let us take the military domain. If there was a choice between finding a universal definition of peace and developing a supergun, what would a politician choose? Agreeing on universal conditions of peace would require a definition of peace as a starting point, and from there, a promising strategy would need to be explored to share and enforce this definition. However, since ancient historical times, the myth of a super gun has consistently been more appealing culturally, militarily, and politically. And this is true across different cultures and societies. Indeed, today we have nuclear missiles able to destroy a city within a few minutes of launch. We have already achieved the goal of the super gun.

The trend of building fancy military tools did not end with the Cold War, and in fact, it is still going strong today (McFate, 2018). But we have never even come close to finding consensus on the conditions and definition of peace. As harsh as it is, the reason is that it is far easier to replicate the conditions to improve a piece of equipment than it is to produce a particular outcome with humans. The process is compositional, progressively linear in time, and its result is visible and tangible. It is something concrete and, if incomplete, it can be left to the next generation. In addition, it removes the uncertainties of dealing with wavering human emotions, weaknesses, expectations, hopes,

The Journal of Intelligence, Conflict, and Warfare Volume 4, Issue 1 
and arguments. A missile cannot argue against its existence nor against its use. If there is the need for concrete proof of success, machines are a formidable safe investment. These arguments also apply to the use of ESMs over analysts in the process of intelligence analysis.

Intelligence analysis will be increasingly influenced by this dialectic between technology and the human mind, independent from the tangible or intangible benefits that the analysts can produce, as their results are not always measurable. In fact, the temptation to rely on models, analytical tools, and automatic systems to replace human responsibility with something considered more accurate and reliable is dangerous but tempting, as the politicization of such results will be even trickier to detect. Whereas secrecies can always be leaked or disclosed, machine malfunctions or imperfections are less detectable and more inscrutable by analysts; however, the technicians are usually not in a position to judge.

The human ability to be in front of and behind the machines will turn out to be a dangerous option if left to those too inexperienced to judge whether a computer has made a mistake. This is what Stanislav Petrov dared to do in 1983 when the USSR defense missile recognition system went clamorously wrong. Judging it to be a technical error, Petrov refused to report the machine's announcement of a supposed first strike from the USA of five nuclear missiles (Hoffman, 2009), thus avoiding a potential Soviet retaliation scenario. Leaving such a future scenario up to chance is far from being a wise idea and could instead prove to be a weak link. Would we, by happy accident, find someone like Petrov in a similar circumstance today? Would we be more likely to trust ourselves than the latest ESM technology?

\section{Conclusion}

Current technological development will not eliminate the need for intelligence analysis and analysts. However, it will reshape the future of analysts' work. Analysts will need to use more and more technologies and will have to learn to create new ESMs. Only this way, will they survive the ongoing technological environment in which the forest of ESMs will overwhelm the field, developing without clear direction or control. This will be a spontaneous expansion of the current conception of technology and its role in intelligence analysis.

However, there is still the need for human-driven intelligence analysis in the scenario of a 'cleaned up version' of what technology is and will be. The temptation is always to remove the natural friction posed to tools. Do we always trust the machines? To what extent? How can we be sure they are doing the right thing? Do we want to put our nations' security in the hands of blind machines?

The Journal of Intelligence, Conflict, and Warfare Volume 4, Issue 1 
Without appropriate checkpoints, critical evaluation, and human understanding, there is no way to control their outputs. Turing (1950) was the first who stated clearly that we could not trust the machines if we do not have access to their mechanical/informational procedures. After all, he argued, we cannot assume their infallibility. Nothing is infallible in nature, and human technology is no exception.

We tend to overestimate machine results because it is cheaper and easier to do so. The challenge is that there is already a curtain of software in front of us, and nobody is able to clearly define or mitigate its appropriate use. Removing the human factor seems a more comfortable way to mollify, but not solve, the issue; it appears easier to develop new tools rather than invest in hiring and training, and there is always the temptation to think someone else knows better than us regarding what is good or right. Investing in new technology, commonly sold as the answer for analytic troubles, is less risky in the short run and is what the history of the last century managed to perfect. While the start of the $21^{\text {st }}$ century embraced a new mythology — which has already twice diverged from sheer triumphalism to sheer apocalypticism-in all its upheaval, the universal laws did not change; therefore, we need responsible and active intelligence analysts as never before. 


\section{References}

Arcos, R., Palacios, J.M. (2020). EU INTCEN: a transnational European culture of intelligence analysis? Intelligence and National Security, 35(1), 72-94. DOI: 10.1080/02684527.2019.1649912

Artner, S., Girven, R., \& Bruce, G. (2016). Assessing the value of structured analytic techniques in the U.S. intelligence community. RAND Corporation. https://www.rand.org/pubs/research_reports/RR1408.html

Baker, D. (1995). Deep attack: A military intelligence task force in Desert Storm. In J. Finley (eds.), U.S. army military intelligence history: A sourcebook (pp. 341-347). US Army Intelligence Center and Fort Huachuca.

Beaney, M. (2018). Analysis. In E. N. Zalta (ed.), The Stanford encyclopedia of philosophy (Summer 2018 Edition). Stanford University. https://plato.stanford.edu/archives/sum2018/entries/analysis/

Coulthart, S. (2016). Why do analysts use structured analytic techniques? An in-depth study of an American intelligence agency. Intelligence and National Security, 31(7), 933-948.

Dawkins, R. (1976). The selfish gene. Oxford University Press.

Dawkins, R. (2016). Extended phenotype. The long reach of the gene. Oxford University Press.

Floridi, L. (2010). Information - A very short introduction. Oxford University Press.

Floridi, L. (2011). Enveloping the world for AI. The Philosophers' Magazine, 54, 20-21.

Floridi, L. (2019). What the near future of artificial intelligence could be. Philosophy \& Technology, 32(1), 1-15.

Gartin, J. (2019). The future of analysis. Studies in Intelligence, 63(2), 1-6.

Goodman, M., \& Omand, D. (2008). What analysts need to understand: The King's intelligence studies program. Studies in Intelligence, 52(4), 112.

Hare, N., \& Coghill, P. (2016). The future of the intelligence analysis task. Intelligence and National Security, 31(6), 858-870, DOI: 10.1080/02684527.2015.1115238

The Journal of Intelligence, Conflict, and Warfare Volume 4, Issue 1 
Heuer, R., (1999). Psychology of intelligence analysis. Center for the Study of Intelligence. Central Intelligence Agency.

Heuer, R. \& Pherson, R. (2015). Structured analytic techniques: A new approach to analysis. In R.Z. George, \& J.B. Bruce (Eds.), Analyzing intelligence (pp. 231-248). Georgetown University Press.

Hoffman, D. (2009). The dead hand: The untold story of the Cold War arms race and its dangerous legacy. Anchor-Random House.

Kasparov, G. (2018). Chess, a drosophila of reasoning. Science, 362(6419), 1087. DOI: $10.1126 /$ science.aaw2221

Kent, S. (1951). Strategic intelligence for American world policy. Princeton University Press.

Kreuzer, M. (2015). Professionalizing intelligence analysis: An expertise and responsibility centered approach. Intelligence and National Security, 31(4), 579-597.

Lowenthal, M. (2008). Towards a reasonable standard for analysis: How right, how often on which isssues? Intelligence and National Security, 23(3), 303-315.

Marrin, S. \& Cienski, S. (2019). Experimenting with intelligence education: Overcoming design challenges in multidisciplinary intelligence analysis programs. In L. Gearon (Ed.), The Routledge international handbook of universities, security and intelligence studies (pp. 287299). Routledge.

Marrin, S. (2007). Intelligence analysis theory: Explaining and predicting analytic responsibilities, Intelligence and National Security, 22(6), 821-846.

McFate, S. (2018). The new rules of war - Victory in the age of durable disorder. HarperCollins Publishers.

Mises, L. (1949). Human action: A treatise on economics. Mises Institute. https://mises.org/library/human-action-0

Modern War Institute. (2018, December 3). Can 'deep thinking' defeat tomorrow's adversaries - Class of 2006 WSC [Video]. Youtube. https://youtu.be/QSyKlzh9Z18

Odom, W. (2008). Intelligence analysis. Intelligence and National Security, 23(3), 316-332.

Pili, G. (2015). Filosofia pura della guerra. Aracne.

The Journal of Intelligence, Conflict, and Warfare Volume 4, Issue 1 
Pili, G, (2019a). Is a chess player and intelligence analyst? How to learn from chess how to improve intelligence analysis. American Intelligence Journal, 36(2), 74-85.

Pili, G. (2019b). Intelligence and social epistemology - Toward a social epistemological theory of intelligence. Social Epistemology, 33(6), 574-592. https://doi.org/10.1080/02691728.2019.1658823

Scuola Filosofica. (2020a). An interview on open source intelligence with Efren Torres, scholar and intelligence practitioner. https://www.scuolafilosofica.com/8944/efren-torres

Scuola Filosofica. (2020b). William Spracher | Intelligence education and the American intelligence journal | Intelligence \& interview N.17| Dr. Giangiuseppe Pili. https://www.scuolafilosofica.com/9089/william-spracherintelligence-education-and-the-american-intelligence-journalintelligence-interview-n-17-dr-giangiuseppe-pili

Silberg, J. \& Manyika, J. (2019, June 6). Notes from the AI frontier:

Tackling bias in AI (and in humans). McKinsey Global Institute. https://www.mckinsey.com/featured-insights/artificialintelligence/tackling-bias-in-artificial-intelligence-and-in-humans

Silver, D., Hubert, T., Schrittwieser, J., Antonoglou, I., Lai, M., Guez, A., Lanctot, M., Sifre, L., Kumaran, D., Graepel, T., Lillicrap, T., Simoyan, K., \& Hassabis, D. (2018). A general reinforcement learning algorithm that masters chess, shogi, and go through selfplay. Science, 362(6419), 1140-1144. DOI:10.1126/science.aar6404.

Smith, B. (2012). How to do things with documents. Rivista di Estetica 50(2), 179-198.

Smith, B., \& Ceusters, W. (2015). Aboutness: Towards foundations for the information artifact ontology. ICBO.

Treverton, G., \& Gabbard, B. (2008). Assessing the tradecraft of intelligence analysis. RAND Corporation. https://www.rand.org/pubs/technical_reports/TR293.html

Turing, A. M. (1950). Computing Machinery and Intelligence. Mind, 43, 433-460.

Warner, M. (2002). Wanted: A definition of 'intelligence'. Studies in Intelligence, 46(3), 15-22.

Wittgenstein, L. (1951). Philosophical investigations. Translated by G. E. M. Anscombe. Macmillan.

The Journal of Intelligence, Conflict, and Warfare Volume 4, Issue 1 
Yergin, D. (2012). The prize - The epic quest for oil, money \& power. Simon \& Schuster.

\section{Author Biography}

Giangiuseppe Pili is a research member of Intelligence Lab - Calabria University and a former lecturer in the International Master in Security, Intelligence and Strategic Studies at Dublin City University in Ireland. He earned a Ph.D. in philosophy from Università Vita-Salute San Raffaele (Milan, Italy). He is an editorial board member of the Italian Society of Intelligence and host of the series "Intelligence \& Interview". He is also the Editor of a collective series of books on applied philosophy based on the blog Scuola Filosofica. Along with Professor Mario Caligiuri, he is the author of the book Intelligence Studies (2020), which was included in the official digest of the Italian Secret Services (DIS). The author can be contacted at giangiuseppe.pili@socint.org.

(c) (i) ()

EY NC ND This work is licensed under a Creative Commons Attribution-

NonCommercial-NoDerivatives 4.0 International License.

(C) (GIANGIUSEPPE PILI, 2021)

Published by the Journal of Intelligence, Conflict, and Warfare and Simon Fraser University

Available from: https://jicw.org/

The Journal of Intelligence, Conflict, and Warfare Volume 4, Issue 1 